\title{
Self-Management Program to Adapt with Multiple Sclerosis Problems and Enhance Quality of Life
}

\author{
Amany Mohamed Saad ${ }^{1} \&$ Enas Ebrahiem Elsayed ${ }^{2}$ \\ 1. Assistant Professor of Community Health Nursing, Faculty of Nursing, Helwan University, Egypt. \\ 2. Lecturer of Adult Health Nursing, Faculty of Nursing, Helwan University, Egypt.
}

\begin{abstract}
:
Multiple sclerosis is a complicated disease that has a major impact on quality of life. Self-management is necessary for carrying out active and emotional satisfaction of life to enable patients to be independent. Aim: To examine the effect of self-management program to adapt with multiple sclerosis problems and enhance quality of life. Design: A quasi-experimental design was utilized. Setting: The study was done at Multiple Sclerosis Outpatient Clinic, Ain Shams University Hospitals. Sample: A purposive sample includes 90 patients. Tools: A structured interview questionnaire was used, it include four parts: Patient's demographic characteristics, previous medical history and present health problems, patients knowledge, and Multiple sclerosis quality of life. Results: About two fifths of patients had poor knowledge pre program, this improved to nearly two thirds of them had good knowledge post selfmanagement program. About half of patients had low quality of life pre self-management program, this improved to one fifth of them had high quality of life post program. There was highly statistically significant correlation between total knowledge of patients and their quality of life pre and post self-management program ( $\mathrm{p}$ value $<0.01$ ). Conclusion: Self-management program reduced health problems of multiple sclerosis patient and enhance their knowledge and quality of life. Also there were a significant correlation between knowledge and quality of life among multiple sclerosis patients. Recommendations: Increase awareness about coping strategies of multiple sclerosis problems for patient and their family. And booklet about enhancement quality of life for multiple sclerosis patients should be available in all multiple sclerosis outpatient clinics.
\end{abstract}

\section{Keywords: Multiple sclerosis problems, Self-management program \& Quality of life.}

\section{Introduction:}

Multiple sclerosis (MS) is the greatest widespread disabling neurological condition affecting young adults around the world. MS can develop at any age, but common among the ages of 20 and 50 years. This inflammatory disorder is with the global occurrence of 33/100,000. Incidence has increased substantially in many areas since 1990, especially in low and middle income countries through the globe imposing a significant economical and health care burden (Browne et al., 2014) \& (Karikari et al., 2018).

Multiple sclerosis is an incurable illness of the central nervous system that can affect the brain, spinal cord and optic nerves (Better Health, 2014). Symptoms are unpredictable and vary greatly from patient to patient, and from time to time in the same patient. This can cause many problems either physical as: Fatigue, absence of coordination, weakness, tingling, decreased sensation, vision problems, bladder, bowel, and sexual problems, psychological as: Cognitive impairment and mood changes, and social as: The embarrassment of dealing with people as a result of difficulty speaking and isolation. MS disease is not a fatal for majority of patients (Eades, 2014).
Cause of MS is still not known, but researches indicate that a combination of several factors may be involved as: Immunologic, environmental, infectious agent and genetic (Laura, 2019). No single test can diagnose MS but the medical history, neurologic exam and lab tests help healthcare providers rule out other diseases and confirm the MS diagnosis. The complications of MS range from mild to severe. It range from fatigue to the inability to walk. Other problems comprise loss of vision, balance, and bowel or bladder control; depression that results from living with a chronic disorder. There's no cure for multiple sclerosis. However, treatments can improve speed recovery from attacks, modify the progress of the disease and manage symptoms (Health Encyclopedia, 2020).

Multiple sclerosis has a great influence on health related quality of life, and the patient's health status (Jongen, 2017). Quality of life refers to patient awareness of life in the context of the culture and values system who live in, as well in relation to their goals, expectations, and concerns. It has many apparent merits in chronic illness outcome and measure the gradual improvement rather than complete cure, considering a wide range of aspects of daily living (Ysrraelit et al., 2018). 
Self-management is the individual's ability to manage the symptoms, treatment, physical and psychosocial consequences and lifestyle changes to living with a chronic condition. Self-management program support and help patients and families acquire the skills to manage their illness, providing routine assessing problems and accomplishments. It is a potential approach that may diminish the symptoms related to MS. As well it is a new phenomenon in the health research field but are seen as important to active management for long-term diseases (Kidd et al., 2017). Self-management program is important for MS patients for adaptation with the disease problems to keep or restore their function, enhance self-efficacy and increase their confidence in performing their activities. Furthermore, these skills also assist patients to form a partnership with their health care providers to improve the management of chronic illnesses problems and quality of life (Tahajjodi et al., 2015).

Nurses play a crucial role in helping patients with MS to understand their disease as well as assisting with treatment initiation, monitor, management and encourage long-term adherence to therapy. Also they are counseling, supporting, and educating patients about the available treatment options (Mynors \& Bown, 2014). One of the most important responsibilities of the nurse is to educate patients and society regarding the multiple sclerosis disease and the interventions that assist them to adapt with their disease problems and deal with the restrictions on their daily lives and improve quality of life (Braine \& Cook, 2015).

\section{Significance of the study:}

Multiple sclerosis is an autoimmune inflammatory illness leading to demyelination and neurodegeneration. It is the second cause of disability after car accidents, affecting young adults and impairs their quality of life during their productive life (Jongen, 2017). MS affects approximately more than 2.3 million people globally (Hassan, 2018). It is estimated that over 130,000 people are living with MS in the United Kingdom, with nearly 7,000 new cases diagnosed each year (Thompson et al., 2017). In a previous Egyptian retrospective meta-analysis study the prevalence of MS in Egypt was found to be 14.1/100,000 (El- Tallawy et al., 2016).

Most patients with MS progressively become disabled over the course of the disease. These disabilities affect the independence of them. About $60 \%$ of MS patients will depend on mobility aids after 20 years on average from the beginning of the illness (Hemmatpoor et al., 2018). Patients who can use self-management have the best chance of effective adaptation to the challenges posed by chronic disease problems; because MS patients' quality of life can deteriorate and loss their independence and become less able to participate in social activities. Therefore, this research was proposed to evaluate the effects of self-management program to adapt with multiple sclerosis problems and enhance quality of life.

Aim of the study

The aim of this study was to evaluate the effect of self-management program to adapt with multiple sclerosis problems and enhance quality of life.

This was achieved through the following objectives:

1. To assess health problems of MS patients and their knowledge about multiple sclerosis.

2. To plan and implement self-management program for MS patients to adapt with disease problems and enhance quality of life for them.

3. To appraise the effectiveness of selfmanagement program for patients with multiple sclerosis.

The research hypotheses

1. The self-management program will improve patients knowledge about multiple sclerosis.

2. The self-management program will improve quality of life for patients with multiple sclerosis problems.

3. There will be a significant correlation between knowledge and quality of life among multiple sclerosis patients.

\section{Subjects and Methods}

Design: A quasi experimental design was utilized.

Setting: The study sample was recruited by the researchers from the Multiple Sclerosis Outpatient Clinic, Ain Shams University Hospitals, Egypt.

Sample: A purposive sample involved 90 patients from the total number of patients (128) that attended in the previous year in the above mentioned setting, they were selected according to the following inclusion criteria:

- Diagnosed with multiple sclerosis

- Age from 20 to 50 years.

- Accept to participate in the study.

Exclusion criteria:

Patients with mental disease.

The sample size: Was calculated by use power analysis and based on the following formula:

$$
N=\frac{\mathrm{N} \times \mathrm{p}(1-\mathrm{p})}{\left.\left\{\mathrm{N}-1 \times\left(\mathrm{d}^{2} \div \mathrm{z}^{2}\right)\right\}+\mathrm{p}(1-\mathrm{P})\right\}}
$$

- Type I error with significant level $(\alpha)=0.5$.

- Type II error by power test $=90 \%$. (Suresh $\boldsymbol{\&}$ Chandrashekara, 2012).

Tools for date collection.

Tool I: A structured interview questionnaire (pre and posttest): This tool was developed by the researchers in a simple Arabic language after reviewing the recent and relevant literature, it included the following parts: 
Part I: Patient's demographic characteristics: It include: Age, gender, marital status, educational level, place of residence and occupation.

Part II: Patient's previous medical history and present health problems related to multiple sclerosis (physical, psychological and social health problems).

Part III: Patient's knowledge: It was developed by the researchers to assess levels of patients' knowledge about multiple sclerosis as: Meaning, incidence, causes, risk factors, sign and symptoms, diagnosis, types, complications, treatment, precaution to prevent recurrence MS, how to cope with MS and its pain, and regular follow up. It consist of 13 questions.

Scoring system for knowledge: The obtained knowledge was checked with a model answer and the patients` responses were scored as follows:

- Correct answer $=1$ grade and incorrect answer $=$ zero.

The total score was converted into percentage and categorized as the follows:

- Poor knowledge $<50 \%$ scored from 0-6

- Average knowledge 50-<75\% scored from 7-9

- Good knowledge $\geq 75 \%$ scored from 10-13 (ElKattan \& El-Zayat, 2019).

Part IV: Multiple Sclerosis Quality of Life (MSQOL)-54 Instrument: It was adapted from Barbara, Vickrey (1995) \& Samohyl (2014) and modified by the researchers, to assess quality of life for patients with multiple sclerosis.

Scoring system: It was consists of 54 items includes all domains of quality of life. There are 14 subscales as (physical function contains 10 items, role limitation physical contains 4 items, role limitation emotional contains 3 items, bodily pain 3 items, emotional wellbeing 5 items, energy 5 items, health perceptions 5 items, social function 3 items, cognitive function 4 items, health distress 4 items, sexual function 4 items, change in health 1 item, satisfaction with sexual function 1 item, and overall quality of life contains 2 items). The patients answer the most accurate response for them it ranges from 0-2 points. The total score was 108 grades. Patients' responses were scored as the following: (Never $=0$, Sometimes $=1, \&$ Always $=2$ ) The total score was converted into percentage as follows:

- Low quality of life $<50 \%$ with score from 0-53

- Average quality of life $(50-<75 \%)$ with score from 54- 80

- High quality of life $\geq 75 \%$ with score from 81 108

Content validity:

Testing validity of the study tools were revised by a panel of five experts in the field of Community Health Nursing and Medical Surgical Nursing to ascertain their clarity, face, completeness and relevance of the content. According to the opinion of the expertise, minor modifications were done on the form of rephrasing and comprehension.

\section{Reliability of the tools:}

Reliability was tested to determine the extent to which the questionnaire items are related to each other. The Cronbach's alpha for knowledge items = 0.874 and for MS quality of life items $=0.911$.

Pilot study:

A pilot study was conducted on $10 \%$ (9) of the study sample to examine the applicability, and clarity of the tools, as well to assess the necessary time for filling in the tools before starting the actual data collection. According to the results of the pilot study, no modifications were done on the tools. So, those patients were included in the main study sample. $\ddot{0}$

The aim of the study was explained to the hospital manager to get endorsement to carry out this study in Multiple Sclerosis Outpatient Clinic. As well, the researchers clarified the aim of the study to each patient and got consent regarding participation in the study. They were assured that the obtained data will be remained confidentially and used only for the research purpose. They were also informed that they have the right to withdraw from the study at any time without any reason.

\section{Administrative design:}

The official approval were obtained from the directors of Ain Shams Hospitals to conduct the study in the Multiple Sclerosis Outpatient Clinic. Letters of request were issued from the Faculty of Nursing, Helwan University to them covering the aim of the study and its expected outcomes.

Field work:

After obtaining the permission to conduct the study, the researchers introduced themselves to the patients and clarified the aim of the study. The oral consent was obtained from the participants. The collection of data took a period of six months from the $1^{\text {st }}$ of June to the end of November 2020 for pre test, program implementation and post test, about 20-25 minutes were required to complete the tools. The researchers were present in the study setting, two days per week, from 9.30 a.m. to 1.00 p.m.

The application of self-management program was carried out through four phases:

Assessment phase:

The initial phase was done by using the pre-test after the approval taken to conduct the study, the researchers interviewed the patients and presented themselves for them, and they clarified the aim of the study. An analysis of the pretest data was help in the design of self-management program.

Planning phase: The self-management program was prepared regarding general objective to enhance 
quality of life for MS patients to adapt with disease problems, this achieved through application of selfmanagement program based on the actual patients' needs as in pre assessment. A booklet was organized by the researchers, in simple Arabic language after reviewing the related literatures. As well, the selfmanagement program met the needs and understanding level of the patients. This booklet include: Meaning of MS, incidence, types, signs and symptoms, risk factors, causes, diagnosis, complications, treatment, tips for teaching the client and family to live with MS to improve quality of life and what can the patients do to adapt with disease problems.

Implementation phase: The self-management program was executed in 5 months of 6 months. The total number of patients was 90 divided into ten groups, each group included 9 patients, the program was performed in four theoretical sessions for each group. The duration of each session takes about 30-45 minutes according to the presented items. The session started by the summary about what was given in the previous one and the objectives of the new topics, taking into consideration using simple language that suitable for the patients. Motivation and reinforcement techniques were used to enrich the learning. The booklet was distributed to all patients in the beginning of the self-management program implementation. The researchers met the patients in a waiting area in the MS Outpatient Clinic, and perform post- test to evaluate the patient knowledge regarding MS and their quality of life after self-management program. The methods of teaching included a lectures, and small group discussion. Media used were booklet and pictures to clarify some items during the self-management program.

Evaluation phase: Effect of self-management program on the studied patients was evaluated immediately in post-test after the last session for one time only by using the same tools.

\section{Statistical analysis:}

Data collected from the studied sample were revised, coded and entered using Personal Computer (PC). Computerized data entry and statistical analysis were fulfilled using the Statistical Package for Social Sciences (SPSS) version 22. Data were presented using descriptive statistics in the form of frequencies, percentages, Mean and SD. A t-test used to determine if there is a significant difference. A correlation coefficient used to measure a statistical relationship between two variables. P-value $<0.05$ was considered statistically significant.

\section{Results:}

Table (1): Distribution of the Studied Patients According to their Demographic Characteristics $(n=90)$.

\begin{tabular}{|c|c|c|}
\hline Demographic characteristics & No & $\%$ \\
\hline \multicolumn{3}{|l|}{ Age (years) } \\
\hline $20<30$ & 24 & 26.7 \\
\hline $30<40$ & 51 & 56.7 \\
\hline $40 \leq 50$ & 15 & 16.6 \\
\hline Mean \pm SD & & \\
\hline \multicolumn{3}{|l|}{ Gender } \\
\hline Male & 52 & 57.8 \\
\hline Female & 38 & 42.2 \\
\hline \multicolumn{3}{|l|}{ Marital Status } \\
\hline Married & 20 & 22.2 \\
\hline Single & 28 & 31.1 \\
\hline Widowed & 10 & 11.1 \\
\hline Divorced & 32 & 35.6 \\
\hline \multicolumn{3}{|l|}{ Educational level } \\
\hline No read or write & 2 & 2.2 \\
\hline Basic education & 3 & 3.4 \\
\hline Secondary education & 36 & 40 \\
\hline University education or more & 49 & 54.4 \\
\hline \multicolumn{3}{|l|}{ Place of residence } \\
\hline Urban & 53 & 58.9 \\
\hline Rural & 37 & 41.1 \\
\hline \multicolumn{3}{|l|}{ Occupation } \\
\hline Not working & 25 & 27.8 \\
\hline Working & 65 & 72.2 \\
\hline
\end{tabular}


Table (2): Frequency Distribution of the Studied Patients according to their Previous Medical History (n=90).

\begin{tabular}{|l|c|c|c|c|}
\hline \multicolumn{1}{|c|}{ Medical history } & \multicolumn{2}{c|}{ Yes } & \multicolumn{2}{c|}{ No } \\
\cline { 2 - 5 } & No & $\mathbf{\%}$ & No & \% \\
\hline Diabetes mellitus & 4 & 4.4 & 86 & 95.6 \\
\hline Hypertension & 25 & 27.8 & 65 & 72.2 \\
\hline Cardiovascular disease & 25 & 27.8 & 65 & 72.2 \\
\hline Liver disease & 6 & 6.7 & 84 & 93.3 \\
\hline Renal disease & 4 & 4.4 & 86 & 95.6 \\
\hline Cancer & 0 & 0 & 90 & 100 \\
\hline$*$ Other & 31 & 34.4 & 59 & 65.6 \\
\hline
\end{tabular}

N.B: Some patients suffer from more than one disease. * Other = anemia and gastrointestinal disease.

Table (3): Distribution Health Problems related to Multiple Sclerosis as Reported by the Patients (n=90)

\begin{tabular}{|c|c|c|c|c|}
\hline \multirow[t]{2}{*}{ Health problems } & \multicolumn{2}{|c|}{ Present } & \multicolumn{2}{|c|}{ Absent } \\
\hline & No & $\%$ & No & $\%$ \\
\hline \multicolumn{5}{|l|}{ Physical health problems } \\
\hline Loss of appetite & 50 & 55.6 & 40 & 44.4 \\
\hline Weight loss & 25 & 27.8 & 65 & 72.2 \\
\hline Feeling of malaise & 88 & 97.8 & 2 & 2.2 \\
\hline Numbness of extremities & 79 & 87.8 & 11 & 12.2 \\
\hline Urinary tract disorders & 76 & 84.4 & 14 & 15.6 \\
\hline Persistent headache & 38 & 42.2 & 52 & 57.8 \\
\hline Blurred vision & 68 & 75.6 & 22 & 24.4 \\
\hline Motor disorders & 90 & 100 & 0 & 0.0 \\
\hline Gastrointestinal disorders & 52 & 57.8 & 38 & 42.2 \\
\hline Circulatory system disorders & 2 & 2.2 & 88 & 97.8 \\
\hline Respiratory system disorders & 26 & 28.9 & 64 & 71.1 \\
\hline \multicolumn{5}{|l|}{ Psychological health problems } \\
\hline Depression \&frustration & 69 & 77.1 & 21 & 22.9 \\
\hline Mood swing & 76 & 84.4 & 14 & 15.6 \\
\hline Change in eating habits & 87 & 96.7 & 3 & 3.3 \\
\hline Psychological tension & 90 & 100 & 0 & 0.0 \\
\hline lack of concentration & 64 & 71,1 & 26 & 28.9 \\
\hline Insomnia & 78 & 86.7 & 12 & 13.3 \\
\hline Rapid angry & 86 & 95.6 & 4 & 4.4 \\
\hline Difficulty in taking decision & 82 & 91.1 & 8 & 8.9 \\
\hline \multicolumn{5}{|l|}{ Social health problems } \\
\hline $\begin{array}{l}\text { Feeling embarrassment of dealing with people due to } \\
\text { difficulties in speaking }\end{array}$ & 22 & 24.4 & 68 & 75.6 \\
\hline Social isolation & 67 & 74.5 & 23 & 25.5 \\
\hline Inability to go out with the family & 67 & 74.5 & 23 & 25.5 \\
\hline Inability to go to work $(n=65)$ & 24 & 36.9 & 41 & 63.1 \\
\hline Marital life disturbance & 58 & 64.4 & 32 & 35.6 \\
\hline Avoiding family visits & 77 & 85.6 & 13 & 14.4 \\
\hline
\end{tabular}

Table (4): The Statistical Difference Between Pre and Post Self-Management Program for Studied Patients According to their Correct Knowledge Items about Multiple Sclerosis (n=90)

\begin{tabular}{|c|c|c|c|c|c|c|}
\hline \multirow{2}{*}{ Knowledge items } & \multicolumn{2}{|c|}{ Pre Program } & \multicolumn{2}{|c|}{ Post Program } & \multirow{2}{*}{ T test } & \multirow{2}{*}{ p-value } \\
\hline & No & $\%$ & No & $\%$ & & \\
\hline Meaning of multiple sclerosis & 76 & 84.4 & 88 & 97.8 & 7.463 & $<0.01 * *$ \\
\hline Incidence of multiple sclerosis & 71 & 78.9 & 86 & 95.6 & 8.942 & $<0.01 * *$ \\
\hline Causes of multiple sclerosis & 15 & 16.7 & 85 & 94.4 & 14.064 & $<0.01 * *$ \\
\hline Risk factors of multiple sclerosis & 13 & 14.4 & 81 & 90 & 13.800 & $<0.01 * *$ \\
\hline Signs and symptoms of multiple sclerosis & 3 & 3.3 & 80 & 88.9 & 9.874 & $<0.01 * *$ \\
\hline Diagnosis of multiple sclerosis & 5 & 5.6 & 85 & 94.4 & 11.379 & $<0.01 * *$ \\
\hline Types of multiple sclerosis & 28 & 31.1 & 79 & 87.8 & 14.557 & $<0.01 * *$ \\
\hline Complications of multiple sclerosis & 19 & 21.1 & 71 & 78.9 & 10.761 & $<0.01 * *$ \\
\hline
\end{tabular}




\begin{tabular}{|c|c|c|c|c|c|c|}
\hline \multirow{2}{*}{ Knowledge items } & \multicolumn{2}{|c|}{ Pre Program } & \multicolumn{2}{|c|}{ Post Program } & \multirow[b]{2}{*}{ T test } & \multirow[b]{2}{*}{ p-value } \\
\hline & No & $\%$ & No & $\%$ & & \\
\hline Treatment of multiple sclerosis & 4 & $\overline{4.4}$ & 86 & 95.6 & 9.930 & $<0.01 * *$ \\
\hline Precautions that prevent recurrence of multiple sclerosis & 4 & 4.4 & 86 & 95.6 & 10.258 & $<0.01 * *$ \\
\hline How to cope and living with multiple sclerosis & 18 & 20 & 72 & 80 & 12.485 & $<0.01 * *$ \\
\hline Cope with pain & 37 & 41.1 & 53 & 58.9 & 11.067 & $<0.01 * *$ \\
\hline Regular follow up & 11 & 12.2 & 72 & 80 & 9.367 & $<0.01^{* * *}$ \\
\hline
\end{tabular}

$* *$ Highly statistically significant at $p$ value $<0.001$

\section{Total knowledge}

T test: 16.58

$\mathrm{P}$ value $<0.01 * *$

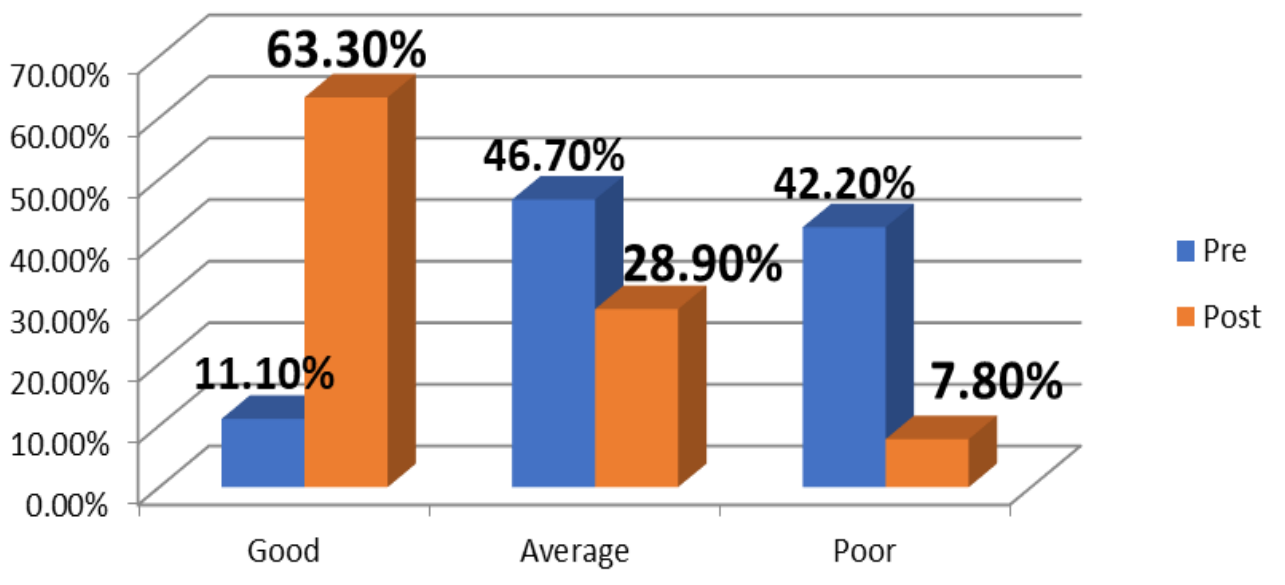

Figure (1): Distribution of Studied Patients According to Total Knowledge Pre and Post SelfManagement Program about Multiple Sclerosis (n=90).

Table (5): The Statistical Difference Between Pre and Post Self-Management Program for Studied Patients According to Their Total Quality of Life Domains about Multiple Sclerosis (n=90)

\begin{tabular}{|c|c|c|c|c|c|c|c|c|}
\hline \multirow{3}{*}{ Quality of life domains } & \multicolumn{3}{|c|}{ Pre Program } & \multicolumn{3}{|c|}{ Post Program } & \multirow{3}{*}{ T test } & \multirow{3}{*}{ p-value } \\
\hline & High & Average & Low & High & Average & Low & & \\
\hline & $\begin{array}{l}\text { No } \\
(\%)\end{array}$ & $\begin{array}{l}\text { No } \\
(\%)\end{array}$ & $\begin{array}{l}\text { No } \\
(\%)\end{array}$ & $\begin{array}{l}\text { No } \\
(\%)\end{array}$ & $\begin{array}{l}\text { No } \\
(\%)\end{array}$ & $\begin{array}{l}\text { No } \\
(\%)\end{array}$ & & \\
\hline Physical function & $\begin{array}{c}7 \\
(7.8)\end{array}$ & $\begin{array}{c}25 \\
(27.8)\end{array}$ & $\begin{array}{c}58 \\
(64.4)\end{array}$ & $\begin{array}{c}12 \\
(13.3)\end{array}$ & $\begin{array}{c}42 \\
(46.7)\end{array}$ & $\begin{array}{c}36 \\
(40)\end{array}$ & 4.862 & $<0.05^{*}$ \\
\hline $\begin{array}{l}\text { Role limitation } \\
\text { physical problems }\end{array}$ & $\begin{array}{c}8 \\
(8.9)\end{array}$ & $\begin{array}{c}28 \\
(31.1)\end{array}$ & $\begin{array}{c}54 \\
(60)\end{array}$ & $\begin{array}{c}13 \\
(14.4)\end{array}$ & $\begin{array}{c}40 \\
(44.4)\end{array}$ & $\begin{array}{c}37 \\
(41.2)\end{array}$ & 3.986 & $<0.05^{*}$ \\
\hline $\begin{array}{l}\text { Role limitation } \\
\text { emotional problems }\end{array}$ & $\begin{array}{c}4 \\
(4.4)\end{array}$ & $\begin{array}{c}33 \\
(36.7)\end{array}$ & $\begin{array}{c}53 \\
(58.9)\end{array}$ & $\begin{array}{c}22 \\
(24.4)\end{array}$ & $\begin{array}{c}38 \\
(42.2)\end{array}$ & $\begin{array}{c}30 \\
(33.4)\end{array}$ & 9.660 & $<0.01 * *$ \\
\hline Bodily pain & $\begin{array}{c}18 \\
(20)\end{array}$ & $\begin{array}{c}42 \\
(46.7)\end{array}$ & $\begin{array}{c}30 \\
(33.3)\end{array}$ & $\begin{array}{c}41 \\
(45.6)\end{array}$ & $\begin{array}{c}34 \\
(37.8)\end{array}$ & $\begin{array}{c}15 \\
(16.6)\end{array}$ & 10.34 & $<0.01 * *$ \\
\hline Emotional well-being & $\begin{array}{c}14 \\
(15.6)\end{array}$ & $\begin{array}{c}48 \\
(53.3) \\
\end{array}$ & $\begin{array}{c}28 \\
(31.1) \\
\end{array}$ & $\begin{array}{c}39 \\
(43.3) \\
\end{array}$ & $\begin{array}{c}37 \\
(41.1) \\
\end{array}$ & $\begin{array}{c}14 \\
(15.6) \\
\end{array}$ & 10.751 & $<0.01 * *$ \\
\hline Energy & $\begin{array}{c}12 \\
(13.3)\end{array}$ & $\begin{array}{c}52 \\
(57.8)\end{array}$ & $\begin{array}{c}26 \\
(28.9) \\
\end{array}$ & $\begin{array}{c}36 \\
(40)\end{array}$ & $\begin{array}{c}28 \\
(31.1)\end{array}$ & $\begin{array}{c}26 \\
(28.9) \\
\end{array}$ & 12.067 & $<0.01 * *$ \\
\hline Health perception & $\begin{array}{c}14 \\
(15.6)\end{array}$ & $\begin{array}{c}39 \\
(43.3)\end{array}$ & $\begin{array}{c}37 \\
(41.1)\end{array}$ & $\begin{array}{c}30 \\
(33.3)\end{array}$ & $\begin{array}{c}38 \\
(42.2)\end{array}$ & $\begin{array}{c}22 \\
(24.5)\end{array}$ & 11.071 & $<0.01 * *$ \\
\hline Social function & $\begin{array}{c}9 \\
(10)\end{array}$ & $\begin{array}{c}51 \\
(56.7)\end{array}$ & $\begin{array}{c}30 \\
(33.3) \\
\end{array}$ & $\begin{array}{l}(25) \\
27.8 \\
\end{array}$ & $\begin{array}{l}53) \\
58.9\end{array}$ & $\begin{array}{l}(12) \\
13.3 \\
\end{array}$ & 10.860 & $<0.01 * *$ \\
\hline Cognitive function & $\begin{array}{c}11 \\
(12.2)\end{array}$ & $\begin{array}{c}53 \\
(58.9)\end{array}$ & $\begin{array}{c}26 \\
(28.9) \\
\end{array}$ & $\begin{array}{c}19 \\
(21.1)\end{array}$ & $\begin{array}{c}51 \\
(56.6)\end{array}$ & $\begin{array}{c}20 \\
(22.3)\end{array}$ & 8.869 & $<0.01 * *$ \\
\hline Health distress & $\begin{array}{c}10 \\
(11.1)\end{array}$ & $\begin{array}{c}52 \\
(57.8)\end{array}$ & $\begin{array}{c}28 \\
(31.1)\end{array}$ & $\begin{array}{c}21 \\
(23.3)\end{array}$ & $\begin{array}{c}53 \\
(58.9)\end{array}$ & $\begin{array}{c}16 \\
(17.8)\end{array}$ & 9.643 & $<0.01 * *$ \\
\hline
\end{tabular}




\begin{tabular}{|c|c|c|c|c|c|c|c|c|}
\hline \multirow{3}{*}{ Quality of life domains } & \multicolumn{3}{|c|}{ Pre Program } & \multicolumn{3}{|c|}{ Post Program } & \multirow{3}{*}{ T test } & \multirow{3}{*}{ p-value } \\
\hline & High & Average & Low & High & Average & Low & & \\
\hline & $\begin{array}{l}\text { No } \\
(\%)\end{array}$ & $\begin{array}{l}\text { No } \\
(\%)\end{array}$ & $\begin{array}{l}\text { No } \\
(\%)\end{array}$ & $\begin{array}{l}\text { No } \\
(\%)\end{array}$ & $\begin{array}{l}\text { No } \\
(\%)\end{array}$ & $\begin{array}{l}\text { No } \\
(\%)\end{array}$ & & \\
\hline Sexual function & $\begin{array}{c}5 \\
(5.6)\end{array}$ & $\begin{array}{c}45 \\
(50)\end{array}$ & $\begin{array}{c}40 \\
(44.4)\end{array}$ & $\begin{array}{c}6 \\
(6.7)\end{array}$ & $\begin{array}{c}46 \\
(51.1)\end{array}$ & $\begin{array}{c}38 \\
(42.2)\end{array}$ & 3.008 & $<0.05^{*}$ \\
\hline Change in health & $\begin{array}{c}7 \\
(7.8)\end{array}$ & $\begin{array}{c}50 \\
(55.6)\end{array}$ & $\begin{array}{c}33 \\
(36.6)\end{array}$ & $\begin{array}{c}16 \\
(17.8)\end{array}$ & $\begin{array}{c}53 \\
(58.9)\end{array}$ & $\begin{array}{c}21 \\
(23.3)\end{array}$ & 4.738 & $<0.05^{*}$ \\
\hline $\begin{array}{lll}\begin{array}{l}\text { Satisfaction } \\
\text { function }\end{array} & \text { with } & \text { sexual } \\
\end{array}$ & $\begin{array}{c}3 \\
(3.3) \\
\end{array}$ & $\begin{array}{c}42 \\
(46.7)\end{array}$ & $\begin{array}{c}45 \\
(50) \\
\end{array}$ & $\begin{array}{c}5 \\
(5.6) \\
\end{array}$ & $\begin{array}{c}46 \\
(51.1)\end{array}$ & $\begin{array}{c}39 \\
(43.3) \\
\end{array}$ & 4.562 & $<0.05^{*}$ \\
\hline Overall quality of life & $\begin{array}{c}3 \\
(3.3) \\
\end{array}$ & $\begin{array}{c}41 \\
(45.6)\end{array}$ & $\begin{array}{c}46 \\
(51.1) \\
\end{array}$ & $\begin{array}{c}18 \\
(20)\end{array}$ & $\begin{array}{c}36 \\
(40) \\
\end{array}$ & \begin{tabular}{|c|}
36 \\
$(40)$ \\
\end{tabular} & 5.068 & $<0.05^{*}$ \\
\hline
\end{tabular}

$* *$ Statistically significant at $p$ value $<0.05 \quad * *$ Highly statistically significant at $p$ value $<0.001$

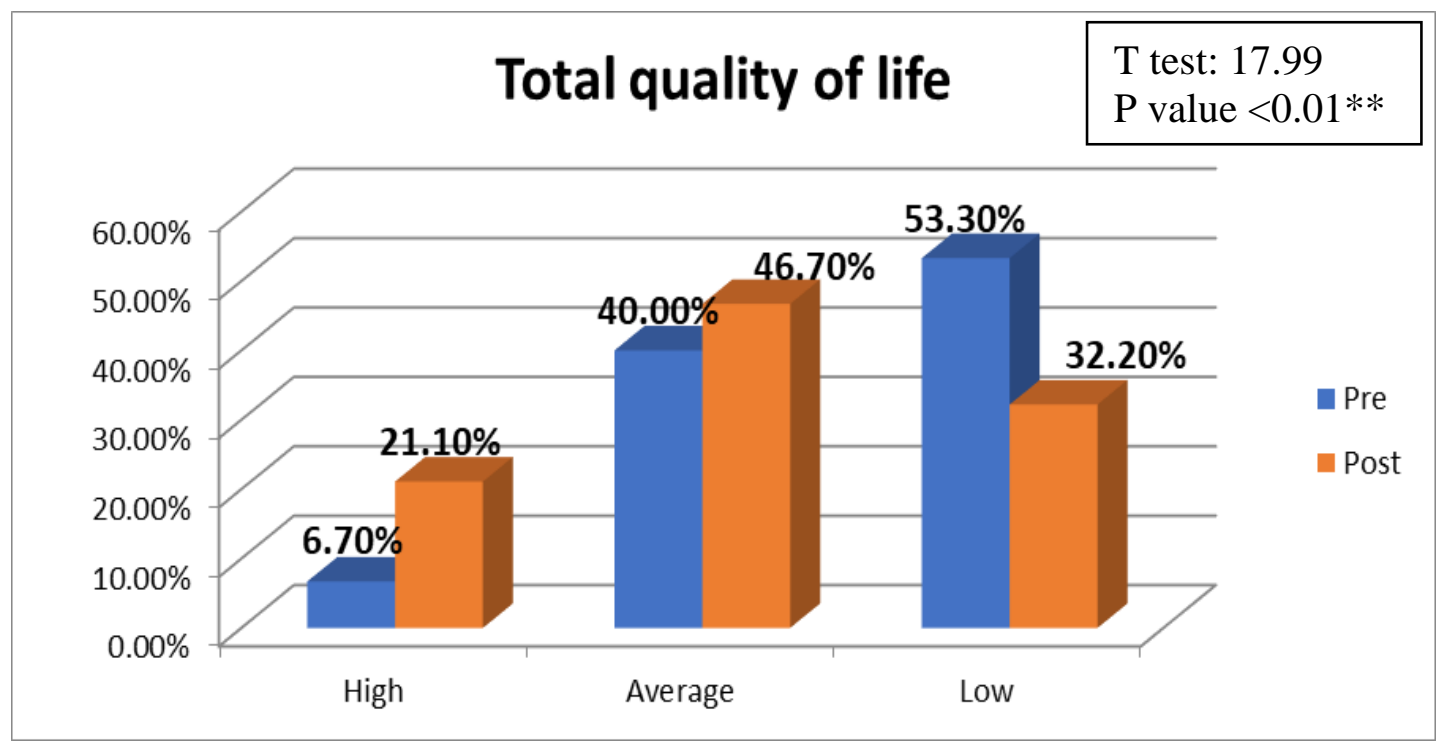

Figure (2): Distribution of Studied Patients According to Total Quality of Life Pre and Post SelfManagement Program about Multiple Sclerosis (n=90).

Table (6): Correlation between Total Knowledge and Total Quality of Life about Multiple Sclerosis Pre and Post Self-Management Program

\begin{tabular}{|l|l|l|}
\hline & \multicolumn{1}{|c|}{ Total knowledge pre } & \multicolumn{1}{c|}{ Total knowledge post } \\
\hline Total quality of life & r. 0.564 & r. 0.611 \\
& P value $<0.01 * *$ & P value $<0.01 * *$ \\
\hline
\end{tabular}

$* *$ Highly statistically significant at $p$ value $<0.01$.

Table (1): Shows that mean age \pm SD of studied patients was $34.16 \pm 5.99,57.8 \%$ of them were male and $35.6 \%$ of them were divorced. According to educational level, $54.4 \%$ of them had university education or more. Related to place of residence and occupation, shows that $58.9 \%$ of them from urban and $72.2 \%$ of them were working.

Table (2): Indicates that $27.8 \%$ of studied patients suffers from hypertension and cardiovascular disease. Also, $6.7 \%$ of them suffers from liver disease and $4.4 \%$ of them suffered from diabetes mellitus and renal disease.

Table (3): Reveals that regarding physical health problems all patients suffers from motor disorder, $97.8 \%$ of them suffers from feeling malaise and $87.8 \%$ of them suffers from numbness of extremities. Concerning psychological health problem, all patients suffers from psychological tension and $95.6 \%$ of them suffers from rapid angry. According social health problems, $74.5 \%$ of them have social isolation and inability to go out with the family. Also $85.6 \%$ of them avoiding family visits.

According to the study hypothesis no (1) which confirmed that self-management program will improve patients knowledge about multiple sclerosis this discussed in table (4) and fig (1) 
Table (4): Displays that $16.7 \%$ and $3.3 \%$ of patient had correct knowledge about causes and signs/symptoms of $\mathrm{MS}$ at pre self-management program, this improved to $94.4 \%$ and $88.9 \%$ post program. Also, $4.4 \%$ of patient had correct knowledge about treatment and precautions that prevent recurrence of MS pre program, this increased to $95.6 \%$ post program, with highly statistically significant difference $(\mathrm{p}$ value $=<0.01)$.

Figure (1): Portrays that $42.2 \%$ of patients had poor knowledge pre program, this improved to $63.3 \%$ of them had good knowledge post program, with highly statistically significant difference ( $\mathrm{p}$ value $<0.01$ ).

According to the study hypothesis no (2) which confirmed that self-management program will improve quality of life for patients with multiple sclerosis problems this discussed in table (5) and fig (2).

Table (5): Demonstrates that $64.4 \%, 60 \%$ and $58.9 \%$ of patient had low quality of life pre self-management program related physical function, role limitation due to physical problems and emotional problem, respectively, this improved to $46.7 \%, 44.4 \%$ and $42.2 \%$ of them had average quality of life at post program. Also, $33.3 \%$ and $31.1 \%$ of patient had low quality of life related social function and health distress pre program, this changed to be $27.8 \%$ and $23.3 \%$ of them had high quality of life post selfmanagement program with highly significant difference ( $p$ value <0.01). Meanwhile, $44.4 \%$ of patient had low quality of life about sexual function pre program this improved to $42.2 \%$ post selfmanagement program with statistically significant difference (p value $<0.05$ )

Figure (2): Illustrates that $53.3 \%$ of patients had low quality of life pre self-management program, this improved to $21.1 \%$ of them had high quality of life post program, with highly statistically significant difference ( $p$ value $<0.01$ ).

According to the study hypothesis no (3) which confirmed that there will be a significant correlation between knowledge and quality of life among multiple sclerosis patients this discussed in table (6).

Table (6): Presents highly statistically significant correlation between total knowledge of patients and their quality of life pre and post self-management program ( $\mathrm{p}$ value $<0.01$ )

\section{Discussion:}

Multiple sclerosis is the most common chronic progressive diseases of the central nervous system, selfmanagement processes can positively affect patients chronic conditions, and make them able to live with their illness, resulting in enhance quality of life (Yamaguchi $\boldsymbol{\&}$ Yatsushiro, 2019).
Regarding patients' demographic characteristics, the results of the current study showed that mean age of studied patients was $34.16 \pm 5.99$ and more than half of them were males. Also the result of the present study revealed that more than half of them had university education. This result is in the same line with Ibrahim et al., (2018) in Sudan, whose study entitled "The patterns of clinical presentation of multiple sclerosis in patients admitted to the national center of neurological sciences, Khartoum, Sudan" who revealed that most of the studied sample were males and most affected age below 40 years. This may be interpreted that the disease usually strikes young adults.

In relation to the place of residence, nearly three fifth of studied patients are from urban area. The study is congruent with Brola et al., (2017) in Świętokrzyskie, whose study about "Multiple sclerosis: Patient reported quality of life in the Świętokrzyskie Region" they revealed that more than half of studied patients were from town. This may be due to the study was conducted at Ain Shams University Hospitals in Cairo, so that most patients were from urban area.

Concerning working nature and marital status, the current study illustrated that nearly three quarters of studied patients were working and about one third of them are divorced. These results are similar to Wendebourg et al., (2017) in Cochrane, whose study entitled "Patient education for people with multiple sclerosis - associated fatigue: A systematic review" whose study results illustrated that more than three quarters of their studied sample were unemployed and nearly three quarters of them were married. Also the current result agreed with Abulaban et al., (2019) in Saudi Arabia, whose study entitled "Multiple sclerosis patients knowledge in Saudi Arabia" they explained that nearly half of studied patients are unemployed. This may be interpreted that multiple sclerosis patients usually suffering from difficulties in motor skills, easily fatigue and cognitive problems, which affect their working abilities,

Regarding the studied patients previous medical history, the current study showed that more than one quarter of patients suffered from hypertension and cardiovascular disease, while minority of them sufferd from liver and renal disease. The study result was in agreement with Alhazzani et al., (2018) in Saudi Arabia, whose study entitled "Quality of life assessment among multiple sclerosis patients in Saudi Arabia" they revealed that more than one quarter of studied patients have a chronic disease e.g (hypertension, diabetes mellitus, and cardiovascular disease).

According to patients health problems related to multiple sclerosis, the current study revealed that there were multiple physical health problems 
affecting multiple sclerosis patients', for example all of them had motor disorder, majority of them feeling malaise and numbness of extremities. These results were congruent with Fasczewski et al., (2017) in North Carolina, whose study entitled "Assessing selfreport physical activity behaviour and quality of life in individuals with multiple sclerosis" they mentioned that more than half of them had a fatigue and malaise due to disease condition, in addition more than one third of them had numbness, neuropathy, and tingling. Also, the study results agreed with Brola et al., (2017) they discovered that more than three quarters of the studied sample had motor and muscular problems related to multiple sclerosis disease. This may be related to the fact about MS disease that affect general health causing fatigue, malaise, and decreased ability to perform ADLs.

Regarding psychological health problems related to multiple sclerosis, the current study revealed that all of studied patients suffered from psychological tension and majority of them have rapid angry. The present study was in the same line with Tauil et al., (2018) in Brazil, whose study entitled "Suicidal ideation, anxiety, and depression in patients with multiple sclerosis"; they revealed that more than one third of studied patients had depression, mood swing and suicidal ideation. This may be related to inability to perform activities of daily living, and acquire persistent job.

Regarding social health problems related to multiple sclerosis, the current findings indicated that nearly three quarters of studied patients had social health problems such as social isolation, and inability to go out with the family and majority avoiding family visits. This result agreed with El-Kattan \& El-Zayat, (2019) in Egypt, whose study entitled "Effects of selfcare education program on quality of life of patients with multiple sclerosis" who study result showed that about three quarters of studied patients had social health problems related to multiple sclerosis. This may be related to physical disorder, fatigue and depression.

Pertaining to patients' knowledge regarding multiple sclerosis at pre and post self-management program, the current results revealed a highly statistically significant improvement in all items of knowledge at post self-management program implementation. This result is congruent with that of Köpke et al., (2017) in Germany, who studied "Patient education program to enhance decision autonomy in multiple sclerosis relapse management" they reported improvement in knowledge after implementation of an education program to the study group in comparing with the control group. Also, This result was consistent with a study prepared by Dahmardeh et al., (2017) in Iran, about "Effect of Orem-based self-care education program on disease-related problems in patients with multiple sclerosis", which stated that the program had its impact on improving the level of knowledge about multiple sclerosis among the intervention group than the control group. This can be interpreted by that the self-management program was effective in promoting the knowledge of patients with multiple sclerosis.

Regarding total knowledge of the studied patients the present study portrayed that about two fifths of patients had poor knowledge pre program, this improved to nearly two thirds of them had good knowledge post self-management program, with highly statistically significant difference. These results were congruent with a study conducted by Mohamadirizi et al., (2017) in Isfahan, Iran. Titled "The effect of electronic education on knowledge of patients with multiple sclerosis", who showed that the application of electronic educational program increased knowledge of patients with MS. This might be related to the positive effect of self-management program.

The above mentioned results verified the research hypothesis no.1, which stated that the selfmanagement program will improve patients knowledge about multiple sclerosis.

The results of the current study demonstrated that nearly about three fifths of patients had low quality of life pre self-management program related physical function, role limitation due to physical problems and emotional problem, this improved to be about slightly more than two fifths of them had average quality of life at post self-management program. This finding in agreement with Sahebalzamani et al., (2012) in Iran, titled "The effects of self-care training on quality of life in patients with multiple sclerosis" who stated that self-care training involved and improved all domains of quality of life, and the differences were significant in both physical and mental domains and the overall quality of life scores.

In relation to total quality of life the current result illustrated that about half of patients had low quality of life pre self-management program, this improved to be one fifth of them had high quality of life post program, with highly statistically significant difference. This finding was in accordance with a study done in United Kingdom by Kidd et al., (2017) about "A systematic review of the effectiveness of self-management interventions in people with multiple sclerosis at improving depression, anxiety and quality of life", who found significant improvement in QOL over time this were reported immediately post intervention and up to 12 months later.

The above mentioned results proved the research hypothesis no.2, which stated that the self- 
management program will improve quality of life for patients with multiple sclerosis problems.

The present study showed that there was highly statistically significant correlation between total knowledge of patients and their quality of life pre and post self-management program. These results were supported by El-Kattan and El-Zayat, (2019), they clarified that there are statistically significant associations between total knowledge and quality of life score post self-care education.

The above mentioned results confirmed the research hypothesis no.3, which stated that there will be a significant correlation between knowledge and quality of life among multiple sclerosis patients.

\section{Conclusion:}

Self-management program reduced health problems of multiple sclerosis patient and promote their knowledge and quality of life. Also there were a significant correlation between knowledge and quality of life among multiple sclerosis patient.

\section{Recommendations:}

- Increase awareness about coping strategies of multiple sclerosis problems for patient and their family.

- Dissemination of the educational programs about regular follow up to minimize recurrence complications of multiple sclerosis patient.

- Booklet about enhancement quality of life for multiple sclerosis patient should be available in all multiple sclerosis outpatient clinics.

- Further research study health care team knowledge or perception about reduce complication and coping with this disease.

\section{References:}

- Abulaban, A., Altowairqi, A., Altowairqi, H., Almutairi, A., Altalhi, S., Alotaibi F. \& Alabbadi, I. (2019): Multiple Sclerosis Patients Knowledge in Saudi Arabia. Neurosciences J., (Riyadh, Saudi Arabia) 24(4):327-330 DOI: 10.17712/nsj.2019.4.20190031.

- Alhazzani, A., Alqahtani, M., Alahmari, M., Asiri, M., Alamri, NL., Alkhashrami, Sh. \& Asiri, A. (2018): Quality of Life Assessment Among Multiple Sclerosis Patients in Saudi Arabia. Neurosciences Journal, 23(2):140-147.

- Braine, M. \& Cook, N., (2015): An evaluation of post-registration neuroscience focused education and neuroscience nurses' perceived educational needs. University of Salford Manchester http://dx.doi.org/10.1016/j.nedt.2015.05.021
- Barbara, G \& Vickrey, M., (1995): Multiple Sclerosis Quality of Life (MSQOL)-54 Instrument. University of California, Los Angeles.

- Better Health. (2014): Multiple sclerosis (MS) common problems - Better Health. Available at: www.betterhealth.vic.gov.au > conditions and treatments.

- Brola, W., Sobolewski, P., Fudala, M., Flaga, S. \& Jantarski, K. (2017): Multiple sclerosis: patientreported quality of life in the Świętokrzyskie Region. Medical Studies J., 33(3):191-198 DOI:10.5114/ms.2017.70345.

- Browne, P., Chandraratna, D., Angood, C., Tremlett, H., Baker, C, Taylor, B, \& Thompson, AJ. (2014): Atlas of multiple sclerosis. A growing global problem with widespread inequity. Neurology. 83(11):1022-4.

- Dahmardeh, H., kianian, T., \& Vagharseyyedin, S. (2017): Effect of Orem-based self-care education program on diseaserelated problems in patients with multiple sclerosis, Zahedan University of Medical Sciences, Zahedan, Iran, Medical-Surgical Nursing Journal; $\quad 6(1)$ : 14-20. https://neoscriber.org/cdn/.../1622ad4a-1a12-11e8a33e-6f0925cad8.

- Eades, J. (2014): Multiple Sclerosis: Its effects on you and those you love. Multiple Sclerosis Society of Canada. Publishing by: Greenwood Tamad Inc. ISBN: $\quad 0-921323-84-0 . \quad$ Available at: www.mssociety.ca. Access date:1/6/2020.

- El-Kattan, B., \& El-Zayat, O. (2019): Effects of Self-Care Education Program on Quality of Life of Patients with Multiple Sclerosis,IOSR Journal of Nursing and Health Science (IOSR-JNHS) e-ISSN: 2320-1959.p- ISSN: 2320-1940 Volume 8, Issue 3 Ser. VII., PP 76-88. Available at: Www.iosrjournals.org.

- Fasczewski, K., Rothberger, S. \& Gill, D. (2017): Assessing Self-Report Physical Activity Behavior and Quality of Life in Individuals with Multiple Sclerosis. SAGE journal, 25(7): 964-975. https://doi.org/10.1177/ 1359105317739965. Accessed date: 6/10/2020.

- El- Tallawy, H., Farghaly, W., Badry, R, Metwally, N., Shehata, G., Rageh, T., Abd El Hamed, M. \& Kandil, M., (2016) : Prevalence of multiple sclerosis in Al Quseir city, Red Sea Governorate, Egypt Neuropsychiatr Dis Treat. 2016; 12: 155-158. Published online 2016 Jan 13. doi: 10.2147/NDT.S87348. PMCID: PMC4716737

- Hassan A. (2018): Living with Multiple Sclerosis in Egypt. Available at: https://www.aljazeera.com/programmes/aljazeeraw orld/2018/10/living-multiple-sclerosis-egypt181007070748295.html 
- Health Encyclopedia. (2020): University of Rochester Medical Center. Available at: https://www.urmc.rochester.edu/encyclopedia/conte nt.aspx? contenttypeid=85\&contentid=P00790

- Hemmatpoor, B., Gholami, A., Parnian, S., \& Seyedoshohadaee, M. (2018): The Effect of Life Skills Training on the Self-Management of Patients with Multiple Sclerosis. Journal of Medicine and Life Vol. 11, Issue 4, October-December 2018, pp. 387 393. DOI: $10.25122 / \mathrm{jml}-2018-0044$.

- Ibrahim, E.A.A., Gassoum, A., Aldeaf, SAH., Ahmed, MO., \& Ahmed, SHA. (2018): The Patterns of Clinical Presentation of Multiple Sclerosis in Patients admitted to the National Center of Neurological Sciences, Khartoum, Sudan. J Neurol Neurosci Vol.9 No.3:258. doi:10.21767/21716625.1000258 .

- Jongen, P., (2017): Health-Related Quality of Life in Patients with Multiple Sclerosis: Impact of Disease-Modifying Drugs

- Karikari, TK, Charway-Felli, A., Höglund, K., Blennow, K., \& Zetterberg, H. (2018): Commentary: global, regional, and national burden of neurological disorders during 1990-2015: a systematic analysis for the global burden of disease study. Front Neurol. 2018;9:201.

- Kidd, T., Carey, N., Mold, F., Westwood, S., Miklaucich, M., Konstantara, E., Sterr, A., \& Cooke, D. (2017): A systematic review of the effectiveness of self-management interventions in people with multiple sclerosis at improving depression, anxiety and quality of life. PLOS ONE 12(10):

$\mathrm{e} 0185931$. https://doi.org/10.1371/journal.pone.0185931

- Köpke, S.J., Kasper, A., Flachenecker, P., Meißner, H.A., Brandt, M.B., Hauptmann, B., Bender, G., Backhus, A., Rahn, A., Pöttgen, J., Vettorazzi, E., \& Heesen, N. (2017): Patient education program to enhance decision autonomy in multiple sclerosis relapse management, University Medical Center, Hamburg-Eppendorf, Hamburg, Germany, Clinical Rehabilitation; 31(2): 250- 261.

- Laura, A. (2019): 4 Possible Causes of Multiple Sclerosis. Available at: https://www.healthline.com/health/multiplesclerosis/possible-causes. Access date:1/7/2020

- Mohamadirizi, S., Shaygannejad, V., Mohamadirizi, Sh, \& Tolou-Ghamari., Z. (2017): The effect of electronic education on knowledge of patients with multiple sclerosis. Journal of Education and Health Promotion | Published by Wolters Kluwer - Medknow;6:10.

- Mynors, G. \& Bown A., (2014): Modelling sustainable caseloads for MS Specialist Nurses. Multiple Sclerosis trust. Spirella Building, Bridge
Road Letchworth Garden City Hertfordshire SG6 4ET Registered charity no. 1088353.

- Sahebalzamani, M., Zamiri, M., \& Rashvand, F. (2012): The effects of self-care training on quality of life in patients with multiple sclerosis. Iranian Journal of Nursing and Midwifery Research | January-February 2012, Vol. 17, Issue 1.

- Samohyl., M. (2014): Quality of health care (in Slovak) postgradualni Med, 16 No. 8, P: 887-892.

- Suresh, K., \& Chandrashekara, S. (2012): Sample size estimation and power analysis for clinical research studies. Journal of human reproductive sciences, 5(1), 7.

- Tahajjodi, R., Parvaneh, S., Ghahari, S., \& Negarandeh, R. (2015): Exploring the selfmanagement strategies in people with multiple sclerosis. Nurs Pract Today. 2015; 2(3): 103-111. Available online at: http://npt.tums.ac.ir

- Tauil, C., Grippe, T., Dias, R., Dias-Carneiro, D., Carneiro, N., Aguilar, A., Silva, F., Felipe Bezera, F., Almeida L., Massarente, V., Giovannelli, E., Tilbery, C h., Brandão, C B., Santos, 1., \& Santos-Neto, L. (2018): Suicidal Ideation, Anxiety, and Depression in Patients with Multiple Sclerosis Arq. Neuro-Psiquiatr, 76 (5):98, Accessed at 2/5/ 2020 at 4 pm. http://dx.doi.org/10.1590/0004282x20180036.

- Thompson, A., Kobelt, G., \& Berg, J., (2017): New insights into the burden and costs of multiple sclerosis in Europe: Results for the United Kingdom. multiple sclerosis journal, vol.23(2S) 204-216.

- Wendebourg, M., Heesen, Ch., Finlayson, M., Meyer, B., Pöttgen, J. \& Köpke, S. (2017): Patient Education for People with Multiple SclerosisAssociated Fatigue: A Systematic Review. PLoS ONE 12(3): e0173025, doi:10.1371/journal. pone.0173025. Accessed at 2/12/2020 at $5 \mathrm{pm}$

- Yamaguchi, S., \& Yatsushiro., R. (2019): Significance and potential of self-management research for HTLV-1 associated myelopathy: review of self-management for people with multiple sclerosis. (J Rural Med 2019; 14(1): 7-25).

- Ysrraelit, M, Fiol, M, Gaitán, M, \& Correale, J. (2018): Quality of Life Assessment in Multiple Sclerosis: Different Perception between Patients and Neurologists. Front. Neurol. 8:729. doi: 10.3389/fneur. 2017.00729. 